Case Report

\title{
Actinomycosis of maxillary antrum presenting as nasal polypi: a rare case
}

\section{K. C. Prasad, Harshitha N.*, Azeem Mohiyuddin S. M., Harshita T. R., Indu Varsha, Vswashanthi Pondala}

\author{
Department of ENT, Sri Devaraj Urs Medical College, Tamaka, Kolar, Karnataka, India
}

Received: 11 October 2018

Revised: 15 June 2019

Accepted: 17 June 2019

\section{*Correspondence:}

Dr. Harshitha N.,

E-mail: twinkle.harshitha@gmail.com

Copyright: (C) the author(s), publisher and licensee Medip Academy. This is an open-access article distributed under the terms of the Creative Commons Attribution Non-Commercial License, which permits unrestricted non-commercial use, distribution, and reproduction in any medium, provided the original work is properly cited.

\begin{abstract}
Actinomycosis is a rare anaerobic bacterial infection that presents in the form of cervicofacial, pulmonary, thoracic and abdominopelvic infections. It is usually caused by Actinomyces israelii which are a part of normal flora of aerodigestive tracts. They are opportunistic pathogens and cause infections which have odontogenic origin in oral cavity. Cervicofacial actinomycosis accounts for more than half of the cases and commonly affects the mandible. We are reporting a case of actinomycosis of left maxillary antrum presenting as a nasal polypi in a young man. He had presented with nasal discharge and yellowish crusts from left nasal cavity. Diagnostic nasal endoscopy revealed yellowish polypoidal mass arising from the left middle meatus. CT PNS showed soft tissue density mass measuring $3.7 \times 4.3 \times 4.1 \mathrm{cms}$ in left maxillary antrum extending through and obliterating osteomeatal complex extending into left ethmoidal sinus. Patient underwent Functional endoscopic sinus surgery. The yellowish polypoidal mass in left nasal cavity was attached to the floor of the maxillary antrum by a thin stalk and had filled up the antrum. Histopathology of the specimen revealed inflammatory polyp with actinomycosis. Patient had an uneventful recovery and was put on long term antibiotics and regular follow up.
\end{abstract}

Keywords: Actinomycosis, Maxillary antrum, Nasal polypi

\section{INTRODUCTION}

Actinomycosis is a rare anaerobic bacterial infection that presents in the form of cervicofacial, pulmonary, thoracic and abdominopelvic infections. It is usually caused by Actinomyces israelii which are a part of normal flora of aerodigestive tracts. They are opportunistic pathogens and cause infections which have odontogenic origin in oral cavity.

Cervicofacial actinomycosis accounts for more than half of the cases and commonly affects the mandible. Most common presentation is in the form of firm mass adjacent to the mandible which breaks down to form multiple abscesses and sinuses, resulting in progressive destruction of connective tissue, muscle and bone. ${ }^{1}$

We are reporting a case of actinomycosis of left maxillary antrum presenting as a nasal polypi in a young man. He had presented with nasal discharge and yellowish crusts from left nasal cavity. Diagnostic nasal endoscopy revealed yellowish polypoidal mass arising from the left middle meatus. CT PNS showed soft tissue density mass measuring $3.7 \times 4.3 \times 4.1 \mathrm{cms}$ in left maxillary antrum extending through and obliterating osteomeatal complex extending into left ethmoidal sinus. There was widening of maxillary ostium, bony remodeling with erosive changes of all walls of maxillary antrum. 
Posteriorly the lesion was extending into infratemporal fat. Patient underwent Functional endoscopic sinus surgery. The yellowish polypoidal mass in left nasal cavity was attached to the floor of the maxillary antrum by a thin stalk and had filled up the antrum. Multiple yellowish patchy areas were found on the posterolateral wall of the left maxillary antrum with intact mucosa and areas of bone erosion. Histopathology of the specimen revealed inflammatory polyp with actinomycosis. Patient had an uneventful recovery and was put on long term antibiotics and regular follow up.

\section{CASE REPORT}

A 29 year old well built man presented with history of left sided nasal discharge and occasional yellowish crusts from left nasal cavity of 6 months duration. He was a known hypertensive on regular treatment. There was no history of nasal obstruction, fever, headache or cough. $\mathrm{He}$ had no previous history of dental extraction or trauma.

Patient was clinically stable and well oriented. Anterior rhinoscopy showed yellowish polypoidal mass in left nasal cavity occupying the space between the middle turbinate and uncinate extending to the floor of the nose. External framework, inferior turbinates and septum was normal. On probing, the mass was soft in consistency, insensitive to touch and was not bleeding on touch. On lifting the mass the mucosa over the septum, floor and roof appeared to be normal. Posterior rhinoscopy was normal. There was no paranasal sinus tenderness. Diagnostic nasal endoscopy showed yellowish polypoidal mass in left nasal cavity arising from left middle meatus.

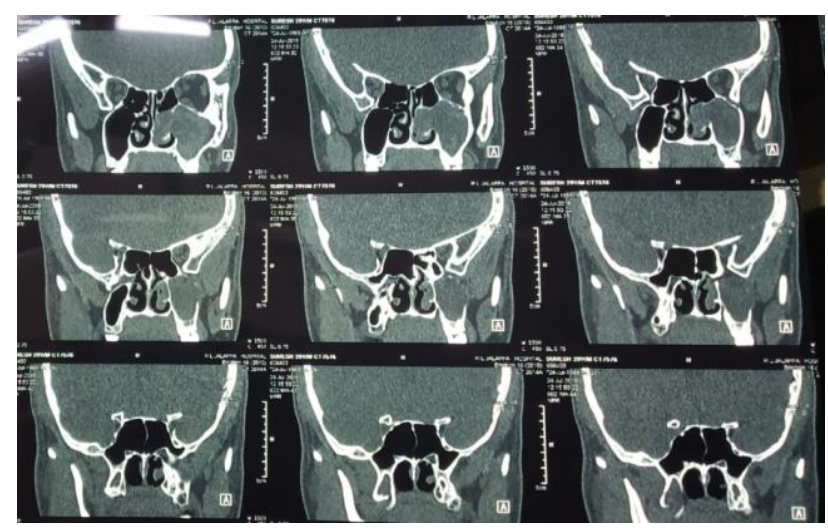

Figure 1: Coronal sections of CT PNS. Soft tissue density mass epicentred in left maxillary antrum extending through osteomeatal complex into left nasal cavity.

CT scan showed soft tissue density mass measuring $3.7 \times 4.3 \times 4.1 \mathrm{cms}$ epicentred in left maxillary antrum extending through osteomeatal complex into left nasal cavity extending superiorly to involve anterior ethmoidal sinuses (Figure 1). There was widening of maxillary ostium, bony remodeling with erosive changes of all walls of antrum (Figure 2). Posteriorly lesion was extending into infratemporal fat. Patient underwent Functional endoscopic sinus surgery. Middle meatal antrostomy was performed. Yellowish polypoidal mass was seen arising from and completely filled the maxillary antrum and attached to the floor by a thin stalk (Figure 3). Multiple yellowish patchy areas present on the posterolateral wall of the left maxillary antrum with intact mucosa, however there were areas of bone erosion on probing (Figure 4). Anterior ethmoidal cells were opened, the secretions and polypoidal mucosa were cleared. Yellowish polypoidal mass from maxillary antrum was removed en bloc (Figure 5). Histopathology of specimen sent revealed actinomyces colonies with areas of necrosis, karyorhectic debris and acute inflammatory cell infiltrate suggestive of inflammatory polyp with actinomycosis (Figure 6). PAS stain was positive for fungal elements. Patient received antibiotics for 3 months and is disease free on regular follow up.

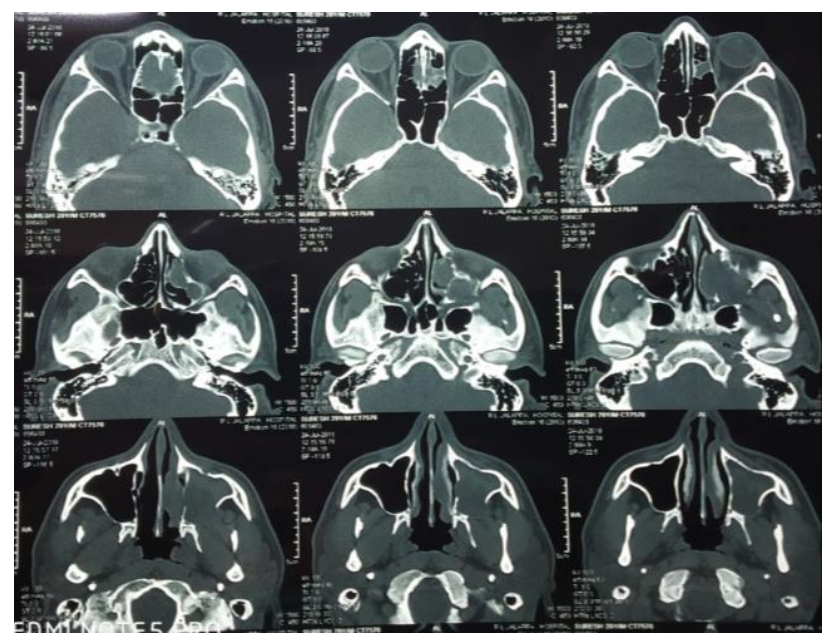

Figure 2: Axial cut sections of CT PNS (widening of maxillary ostium, bony remodeling with erosive changes of all walls of antrum).

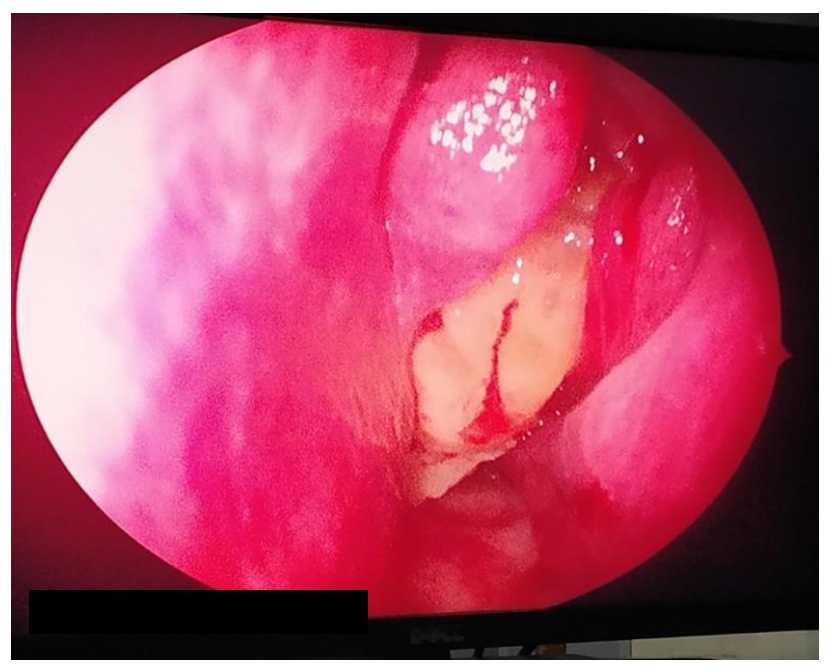

Figure 3: Endoscopic view of left nasal cavity (yellowish polypoidal mass arising from the left middle meatus). 


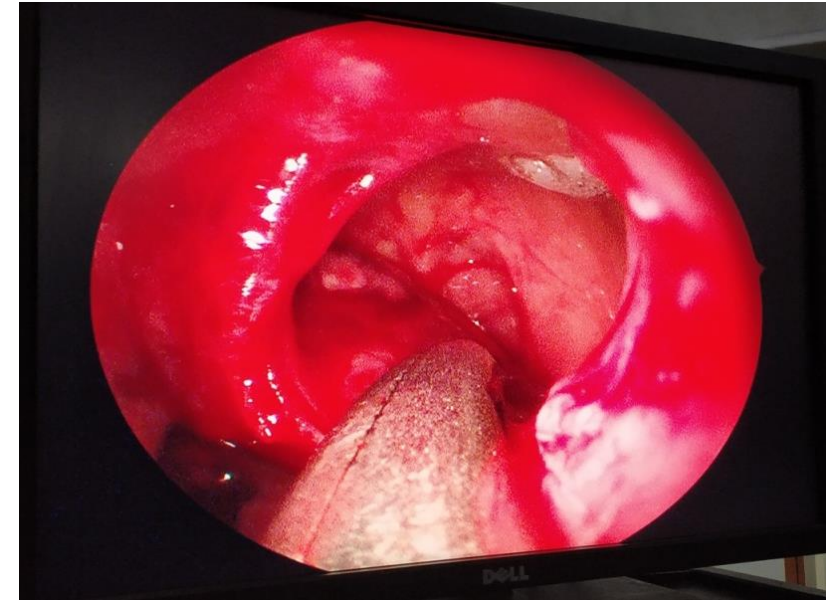

Figure 4: Endoscopic view of left maxillary antrum (multiple yellowish patchy areas present on the posterolateral wall of the left maxillary antrum with intact mucosa and areas of bone erosion on probing).

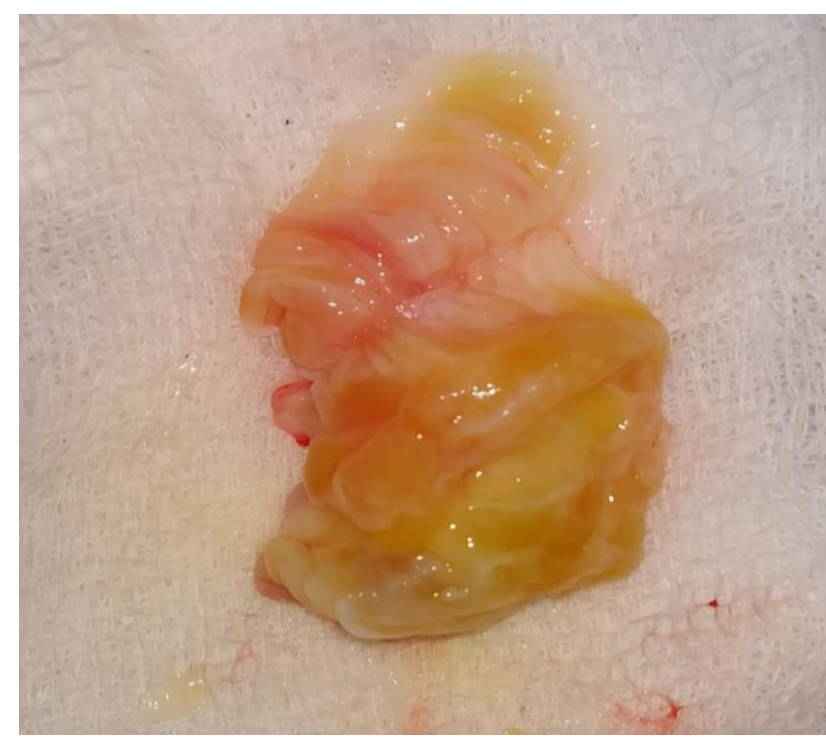

Figure 5: The excised specimen (yellowish polypoidal mass from left nasal cavity).

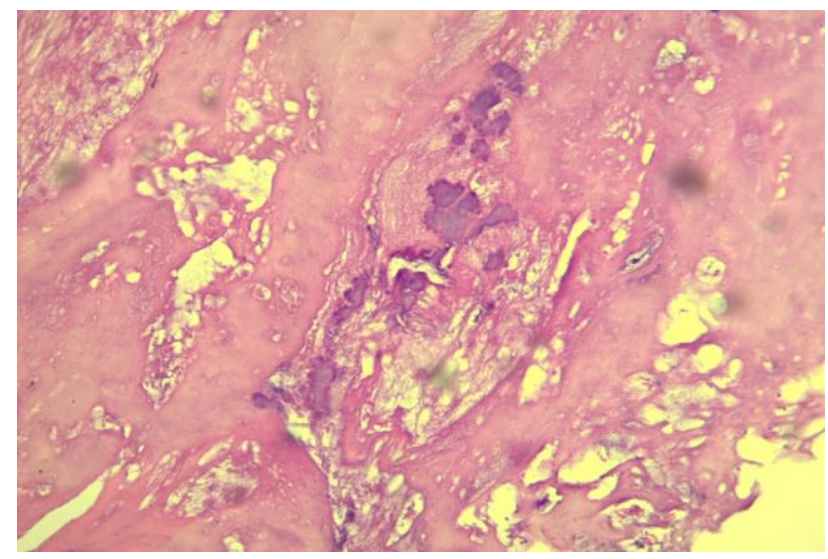

Figure 6: Histopathology image of the specimen excised (actinomyces colonies with areas of necrosis).

\section{DISCUSSION}

Actinomycosis is a rare anaerobic bacterial infection first described by James Israel 200 years ago. Annual incidence is reported to be $<100$ cases globally, therefore clinical suspicion is low leading to a delay in diagnosis and appropriate treatment. ${ }^{1}$

Actinomyces are a gram-positive, anaerobic, non spore forming, non-acid fast bacteria which form a part of normal flora of aerodigestive and female genitourinary tracts. They are often found in tonsillar crypts, in caries teeth, periodontal region and in dental tartar. Actinomyces israeli is the most common species to cause human infections, and belongs to the order Actinomycetales, a group intermediate between the true bacteria and the more complex fungi. ${ }^{1-6}$

This fastidious bacteria has low pathogenicity. Thus infection occurs only in the presence of copathogens and following mucosal injury. Mucosal injuries in the form of infections and trauma, allow the bacteria to reach the subcutaneous tissues, whereas copathogens reduce local oxygen tension, inhibit the host defenses creating an environment favorable for bacterial growth. Spread of the infection occurs by direct invasion progressing extensively across the anatomic barriers, fascial planes, or through lymphatics. ${ }^{1}$

Actinomycosis is a suppurative and granulomatous infection presenting in three clinical forms of cervicofacial, pulmonary and abdominopelvic.?

Cervicofacial actinomycosis is more common in males between second to fifth decades of life and accounts for more than $60 \%$ of cases. It usually affects the mandible. Farmers are the most frequently affected. Infection progresses to form an abscess which breaks down, further leading to sinus tracts and fistulas extruding yellowish drainage containing sulfur granules. ${ }^{7}$ These granules are small pale yellow lobulated flecks of 1-5 mm, composed of gram-positive, non-acid fast mycelia with hyphae growing out towards the periphery giving a radiating appearance which gives the organism its name. Clubs may be present at the periphery composed of antigen antibody complexes. ${ }^{1-4}$

Actinomycosis of paranasal sinuses is a rare manifestation of cervicofacial actinomycosis. This infection is more common in rural women due to hormonal differences and poor oral hygiene. The most common presenting complaints (in $45 \%$ cases) and in the present reported case, are consistent with sinusitis (nasal obstruction, congestion, discharge and postnasal drip) of several months duration. Facial swelling is the second most common presenting complaint in $30 \%$ cases. It presents as unilateral midfacial swelling over the side of the involved sinus. ${ }^{1,5}$ 
Imaging frequently reveals unilateral sinus opacification accompanied by a soft tissue mass with focal calcifications and bony erosion due to the tendency for actinomycosis infections to spread through direct extension without regard for anatomical barriers. ${ }^{1}$

Histologically the lesions consist of confluent nodules in the centre of which are colonies of the Actinomyces. These are surrounded by polymorphs and the periphery of the nodule is composed of granulation and fibrous tissue. ${ }^{3}$

Literature has described the possibility of immunocompromised patients being at higher risk for actinomycosis infection due to the rare incidence even in the presence of constant oral mucosal injury. However actinomycosis has not been reported in patients who receive long term chemotherapy. ${ }^{2}$ Our patient was not immunocompromised and therefore, the relation between actinomycosis and host immune response is not confirmed.

Our patient presented with unilateral polypoidal mass which has not been reported in the literature, however similar opportunistic infection with Nocardia has presented with unilateral ethmoidal polyp. ${ }^{8}$ Clinical symptoms and the findings on physical examination of our patient were similar to that of chronic rhinosinusitis caused by other organisms and our imaging results suggested that PNS actinomycosis can have focal lesions with or without calcification. Actinomycosis is managed by a combination of medical and surgical treatment. Antimicrobials effective on actinomyces include penicillin, chloramphenicol, tetracyclines, macrolides, clindamycin, imipenem, streptomycin, and cephalosporins. ${ }^{2}$ Duration of treatment vary from six weeks to one year depending on the site and severity of infection. $^{2}$

Common complications of cervicofacial actinomycosis are oroantral fistula and osteomyelitis of maxilla. A rare intracranial complication in the form of abducent nerve palsy has been reported. ${ }^{9}$

Our patient has responded well to endoscopic resection of polypoidal mass and clearance. Patient was on antibiotics and frequent saline irrigations for 3 months duration and is disease free noted on frequent follow up.

\section{CONCLUSION}

It is a rare infection caused by a commensal which can be an opportunistic pathogen in immunocompromised. Sinonasal actinomycosis presents with vague symptoms that can initially mimic chronic rhinosinusitis, but can be more aggressive with bone erosion with longstanding infection. This case had a rare presentation with unilateral nasal polypi. Bacterial cultures and pathology are the cornerstones of diagnosis and require high suspicion to prevent misdiagnosis.

\section{Funding: No funding sources \\ Conflict of interest: None declared \\ Ethical approval: Not required}

\section{REFERENCES}

1. Vorasubin $\mathrm{N}, \mathrm{Wu} \mathrm{AW}$, Day $\mathrm{C}$, Suh JD. Invasive sinonasal actinomycosis: case report and literature review. Laryngoscope. 2013;2:334-8.

2. Sánchez Legaza E, Cercera Oliver C, Miranda Caravallo JI. Actinomycosis of the paranasal sinuses. Acta Otorrinolaringol Esp. 2013;4:310-1.

3. Stanton MB. Actinomycosis of the maxillary sinus. J Laryngol Otol. 1966;80(2):168-74.

4. Damante JH, Sant'Ana E, Soares CT, Moreira CR. Chronic sinusitis unresponsive to medical therapy: a case of maxillary sinus actinomycosis focusing on computed tomography findings. Dentomaxillofac Radiol. 2006;35(3):213-6.

5. Sakuma Y, Yamashita Y, Shiono O, Oridate N. Actinomycosis arising from the nasal cavity, with rare fatal progression. BMJ Case Rep. 2016:bcr2015213747.

6. Valour F, Sénéchal A, Dupieux C, Karsenty J, Lustig S, Breton P, et al. Actinomycosis: etiology, clinical features, diagnosis, treatment, and management. Infect Drug Resist. 2014;7:183-97.

7. Meethal AC, Pattamparambath M, Balan A, Kumar NR, Sathyabhama S. Actinomycotic Osteomyelitis of the Maxilla - A Delusive Presentation. Meethal AC, Pattamparambath M, Balan A, Kumar NR, Sathyabhama S. J Clin Diagn Res. 2016;10(7):1-3.

8. Fadda GL, Gisolo M, Crosetti E, Fulcheri A, Succo G. Intracranial complication of rhinosinusitis from actinomycosis of the paranasal sinuses: a rare case of abducens nerve palsy. Case Rep Otolaryngol. 2014:601-71.

9. Padiyar V, Mohiyuddin A, Parimala S. Maxillary Sinusitis and Ethmoidal Polypi due to Nocardia: A Rare Case. Ann Clin Otolaryngol. 2016;1(1):1002.

Cite this article as: Prasad $\mathrm{KC}$, Harshitha N, Azeem MSM, Harshita TR, Varsha I, Pondala V.

Actinomycosis of maxillary antrum presenting as nasal polypi: a rare case. Int J Otorhinolaryngol Head Neck Surg 2019;5:1433-6. 